tures. But we are not yet able, and perhaps we may never be able, at an ordinary temperature, to present the chemist with some other substance derived from calcium, which is not calcium."

Much, of course, remains to be done before Mr. Lockyer's views will be universally accepted. The indecomposable character of the bodies which we have hitherto considered elementary has for a long time been considered doubtful. Mr. Lockyer, however, is the first to come boldly forward with experimental proof. What the final result of the discovery will be we cannot foretell. A physical problem, as Dr. Stewart says, begins like a rivulet. At its first introduction it is small and seemingly unimportant; constantly, however, as it winds along it receives accessions from various quarters, until at length it becomes a mighty river that is finally merged in the unfathomable ocean. This course is followed by all such problems. Each begins small, grows broader, and will finally bear us on to the unknown if we trust ourselves to its guidance.-Journal of Science.

\title{
Carbonic Acid in its Relations to the Winds.-Marié
} Davy states that the quantity of carbonic acid, at Montsouris, in one hundred thousand volumes air of varies between 22 and 36 . He was at first inclined to attribute these variations to the neighboring influence of Paris, which is an abundant source of carbonic acid; while the woods and cultivated fields, at least during the season of vegetation, are an equally active cause of its disappearance. But he found that the northern winds, which come from Paris, contain less carbonic acid, on the average, than the southern winds, which blow directly from the country. He therefore suggests, as an explanation of the phenomenon, that the carbonic acid is found in greater proportion below than above the clonds. The south or southwest winds plough the surface of the ground, but the north or northwest winds plunge from the upper regions of the atmosphere towards the ground. Since 1864 he has thought it important to draw a careful distinction between the equatorial current and the rotary movements which accompany it. The changes of the wind, of the barometer, of the thermometer, and of the hygrometer, are due to the latter, while the proportion of carbonic acid depends upon the former.-Comptes Rendus. 